\title{
The Family Adaptability and Cohesion Evaluation Scale (FACES): an instrument worthy of rehabilitation?
}

\author{
AIMS AND METHOD \\ There have been a variety of \\ instruments developed for \\ evaluating family functioning, but \\ no specific measure has emerged \\ as appropriate for routine clinical \\ use. The Family Adaptability and \\ Cohesion Evaluation Scale (FACES) \\ was viewed as a useful tool for a \\ period, but has been less popular
}

\author{
of late. This paper looks at its use in \\ families with two very different \\ types of problem to assess its \\ discriminatory ability. \\ RESULTS \\ Mothers with depression whose chil- \\ dren were not showing mental health \\ difficulties reported a very different \\ pattern of family functioning from
}

\author{
those whose children were showing \\ chronic school refusal.

\section{CLINICAL IMPLICATIONS} \\ The FACES is capable of discrimi- \\ nating between different patterns of \\ family functioning. Its ease of \\ administration, and the information \\ it provides, should recommend it for \\ wider use in clinical settings.
}

Scientific endeavour is gradually elucidating the influences and pressures that shape a child's functioning, and it is clear that there is a wide range of these, from genetic (Rutter et al, 1999) through to social environments (Place et al, 2002a). One of the most enduring of influences, especially in the earlier phases of life, is the family. Since the 1960s when work began in trying to understand the complexities of family functioning, many theories and approaches have been explored. Their origins have often been from psychological theories, or adaptations of therapeutic approaches which could be applied to families. One of the more initially robust ways of conceptualising families was to describe them using the dimensional constructs of cohesion and adaptability, which was termed the Circumplex Model by its authors (Olson et al, 1979).

Cohesion is defined as the emotional bonding that exists between family members, whereas adaptability is the family's ability to change its power structure, role relationships and rules to respond to situational or developmental needs. Olson and his colleagues developed a particular self-report scale which quantified these dimensions - the Family Adaptability and Cohesion Evaluation Scale, or FACES (Olson et al, 1982). This instrument quickly became one of the standard family assessment tools, and has been used in a large number of projects and clinical evaluations (Olson, 1989). However, in the early 1990s the value of the model began to be questioned (Green et al, 1991), and as approaches such as those based on family narratives have become more popular, the idea of dimensional evaluation has largely disappeared.

However, in clinical practice there is still a need for a method of describing a family's functioning, especially if it permits comparison. We report here the results of using the FACES II questionnaire in two distinct patient groups, and the instrument's ability to discriminate between them.

\section{Method}

\section{Sample}

The first group comprised mothers of 16 children, aged 12-15 years, who were successive referrals to two local education authority provisions that specialised in responding to children who were fearful of attending school. These children all had marked fear of attending school and this had prompted continuous absence for at least 6 months. Children with significant conduct problems were excluded. Each child's functioning was assessed (Place et al, 2002 b) and the family make-up and history was gathered, as well as insight into the family's functioning through the FACES II.

The second group was made up of the first 25 mothers who had been referred to a programme seeking to prevent mental health problems developing in vulnerable children (the resilience study). The criteria for participating in this programme were that the child's parent had to suffer with depression of sufficient severity to require support from a mental health professional. However, the presence of additional problems, such as alcoholism or dual mental health diagnosis, did not prevent the families joining the programme. The second criterion was that the children had to be aged between 7 and 14 years, and the third that the child should have no major mental health problems. The prevention programme (known as Strength to Strength) used a variety of measures to assess functioning (Brownrigg et al, 2004), one of which was the FACES II family evaluation.

The FACES II questionnaire consists of 30 statements that invite family members to comment on relationships and attitudes to family life, such as 'children have a say in their discipline' and 'family members avoid each other at home'. Of the two major parameters of family functioning that are explored, the essence of cohesion is sought through questions such as 'family members know each other's close friends' and 'our family does things 


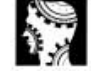

original papers

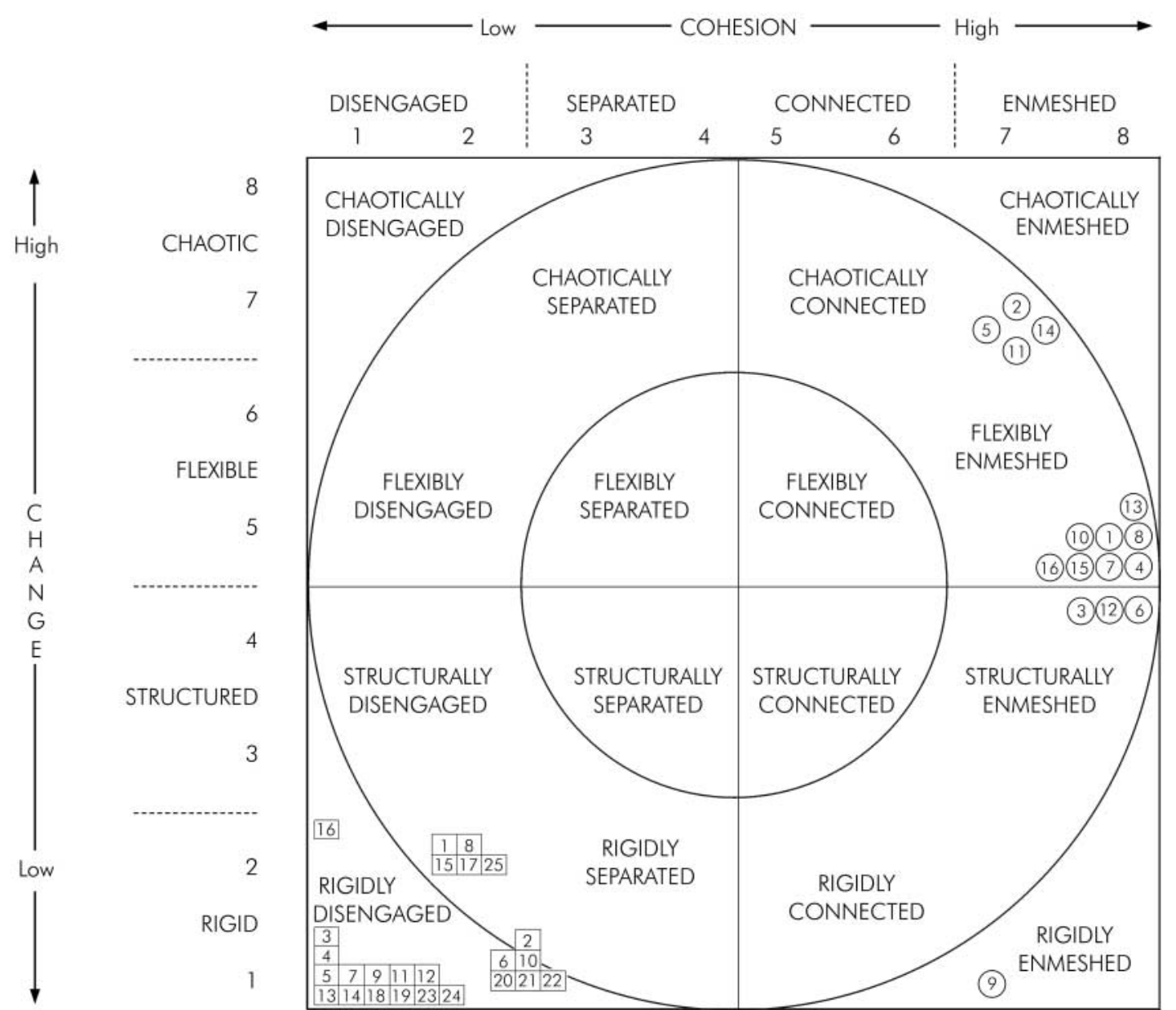

Fig. 1. The FACES scores for the two separate parent groups: $\square$, case from resilience study; $\bigcirc$, case from school refusal study; inner circle, balanced; outer circle, midrange; outside circles, extreme.

together', whereas adaptability is explored through questions such as 'when problems arise we compromise' and 'family members say what they want'. The questions offer both positive and negative aspects of family life, for instance 'it is easier to discuss problems with people outside the family than with other family members', can be contrasted with 'family members discuss problems and feel good about the solutions'. Each statement offers a 5 -point response which ranges from 'almost never', scoring 1, to 'almost always', scoring 5.

The questionnaire was completed in the family home, and if the parent had difficulty with literacy the questions were read out to them. Development work has shown that different family members can offer very different views about family functioning (Olson et al, 1982), but for the purposes of this study the mother was used throughout as the only source of information.

\section{Results}

None of the mothers had difficulty completing the questionnaire, and the results are shown graphically in Fig. 1.
The mothers of the children with school refusal viewed their families predominantly as of the flexibly enmeshed type. By contrast the mothers suffering from depression viewed their families mainly as rigidly disengaged. Table 1 shows the scale of difference in the two scores, with both cohesion and adaptability showing a high degree of statistical significance.

The other significant issue arising from these results is that although over half of the mothers in the school refusal group had significant depressive mental health problems, they did not view their family in the same way as the mothers who were not experiencing school refusal difficulties.

\section{Discussion}

Since the initial work by the Minnesota team, the dimensions of cohesion and adaptability have become bound up with the Circumplex Model proposed by the group. As that model has been criticised so the value of this dimensional evaluation has also been doubted. However, there are no generally accepted, robust definitions for 
Table 1. Comparison of the cohesion and adaptability parameters in the two study groups

\begin{tabular}{|c|c|c|c|c|c|}
\hline & \multicolumn{2}{|c|}{$\begin{array}{c}\text { Mothers of } \\
\text { young people } \\
\text { showing school } \\
\text { refusal } \\
(n=16)\end{array}$} & \multicolumn{2}{|c|}{$\begin{array}{c}\text { Mothers with } \\
\text { depression } \\
(n=25)\end{array}$} & \multirow{2}{*}{$\begin{array}{l}t \text {-test } \\
\text { score* }\end{array}$} \\
\hline & Mean & s.d. & Mean & s.d. & \\
\hline Cohesion & 75.3 & 16.3 & 33.6 & 6.4 & 30.5 \\
\hline Adaptability & 43.1 & 13.3 & 26.2 & 6.9 & 14.7 \\
\hline
\end{tabular}

family dysfunction, and recent work has tended to look more at defined clinical groups (White, 1996), as we report here. Using such groups, the mechanism of evaluating families along the two dimensions of cohesion and adaptability can be explored.

Olson and his team have consistently asserted that the results should be viewed as curvilinear - that is to say that optimal functioning exists among families who achieve moderate rather than extreme scores on the two dimensions (Olson, 1991). However, large scale studies of normal families have tended to report a direct correlation, the higher the score the better the family functioning (Green et al, 1991).

In this study two distinct types of family pattern were reported by the mothers. The depressed mothers' description of rigid disengagement echoes the finding of Olson's validation work with the mothers suffering from depression (Olson et al, 1982), and supports the suggestion that this pattern of family functioning is commonly associated with maternal depression. However, although half the mothers in the school refusal group were clinically depressed they viewed their families quite differently. This suggests that when a child is consistently refusing to go to school this exerts a much stronger influence on the dynamic family relationships than the presence of maternal depression. Indeed previous work with families where a child was consistently refusing to attend school has shown that the relationship between mother and child is dominated by a sense of dependency in the child and overprotection by the mother (Kahn et al, 1996). The results presented here repeat this finding.

The conclusion from this study is similar to that of White (1996) in that the dimensional approach is a useful way of describing family functioning, providing the dimensions are viewed as relatively independent elements rather than trying to use an overall summation as a mechanism for determining the degree of family dysfunction. However, of more obvious significance is the FACES II ability to discriminate between two different types of clinical presentation. The mothers with depression all reported a large degree of emotional detachment within the family, and the reasons for this perception can be used as one element of an intervention programme (Brownrigg et al, 2004). Even if the mother is depressed, these findings indicate that the influences that cause a young person to persistently refuse to attend school are more powerful, and it is tempting to speculate that school refusal can only emerge in an enmeshed family environment.

This strong differentiation of patterns of family life has clear potential implications for clinical practice. Over recent years there has been a growing recognition of the value and effectiveness of family therapy (Cottrell \& Boston, 2002). The results from this study show that the FACES can identify discrepancies in family functioning as perceived by the mothers. This gives an excellent insight into how the mother not only views, but also how she interacts with, the family, which in turn informs therapeutic work. There is no reason to believe that such perceptions are limited to only the mothers within families, and so there is clear opportunity to quantify how various family members perceive, and hence react to, family life through this type of assessment. In addition, a measure of family functioning of this type, which is easy and quick to complete, offers a means of monitoring progress through the therapeutic process. Also from this study comes the insight that, despite similarity in the levels of depression shown by the mothers in both groups, mothers whose children refuse to attend school do view their family life in a very specific way, which in turn points to the importance of ensuring that family work in these cases needs to assume a central role in the treatment package offered.

In conclusion, families are complex systems and it is very difficult to find simple evaluation methods which are of practical assistance to the clinician while offering meaningful information about the family. The results presented here indicate that although using the Circumplex Model to describe family functioning may not seem as robust as it once did, the clinical value of being able to assess adaptability and cohesion within the family is still worthy of consideration.

\section{Declaration of interest}

None.

\section{References}

BROWNRIGG, A., SOULSBY, A. \&

PLACE, M. (2004) Helping vulnerable children to become more resilient. International Journal of Child and Family Welfare, 7, 14-25.

COTTRELL, D. \& BOSTON, P. (2002) Practitioner review: the effectiveness of systemic family therapy for children and adolescents. Journal of Child Psychology and Psychiatry, 43, 573-586.

GREEN, R. G., HARRIS, R. N., FORTE, J. A., et al (1991) Evaluating FACES III and the Circumplex Model: 2240 families. Family Process, 30, 55-73.

KAHN, J., NURSTEN, J. \& CARROLL, H. C. M. (1996) Unwillingly to school: an overview. In Unwillingly to School (eds I. Berg \& J. Nursten), pp.159-173. London: Gaskell.

\section{OLSON, D. H. (1989) Circumplex} Model of family systems: family assessment and intervention. In Circumplex Model: Systemic Assessment and Treatment of Sprenkle \& C. R. S. Russell), pp.7-49. NewYork: Haworth Press.

OLSON, D. H. (1991) Commentary: three-dimensional Circumplex Model Process, 30,74-79. Families (eds D. H. Olson, D. H. and revised scoring of FACES III. Family original papers 
OLSON, D. H., SPRENKLE, D. H. \& RUSSELL, C. R. S. (1979) Circumplex Model of marital and family systems. $\begin{array}{ll}\text { original } & \text { I. Cohesion and adaptability } \\ \text { papers } & \text { dimensions, family types, and clinical }\end{array}$ papers dimensions, family types, and 1 applications. Family Process, 18 3-28.

OLSON, D. H., PORTNER, J. \& BELL, R. Q (1982) FACES II: Family Adaptability and Cohesion Evaluation Scales. Minnesota: Family Social Science, University of Minnesota.
PLACE, M., REYNOLDS, J., COUSINS, A. et al (2002a) Developing a resilience package for vulnerable children. Child and Adolescent Mental Health, 7 162-167.

PLACE, M., HULSMEIER, J., DAVIS, S. et al (2002b) The coping mechanisms of children with school refusal. Journal of Research in Special Educational Needs, 2, 2-10.
RUTTER, M., SILBERG, J., O'CONNOR, T., WHITE, F. A. (1996) Family processes as et al (1999) Genetics and child psychiatry: Il empirical research and Psychiatry, 40, 19-55. predictors of adolescents preferences for ascribed sources of moral authority: a proposed model. Adolescence, 31 144

*Maurice Place Professor of Child and Family Psychiatry, Northumbria University and Consultant Child and Adolescent Psychatrist, Child and Adolescent Mental Health Service, Dover House, Lynn Street, Hartlepool TS24 7LX (e-mail maurice.place@unn.ac.uk), Jessica Hulsmeier Research Associate, Faculty of Social Work and Health, Northumbria, University, Allan Brownrigg Coordinator, Strength to StrengthTeam, City Hospitals, Sunderland, Alison Soulsby Coordinator, Strength to StrengthTeam, City Hospitals, Sunderland 